\title{
Analysis of Emergency Ocular Surgeries during a Pandemic- Experience of a Tertiary Eye Care Centre
}

\author{
Vinitha L Rashme, Sankarananthan R, Madhu Shekhar* and Senthil \\ Prasad \\ Department of Intraocular Lens and Cataract Services, Aravind Eye Hospital and \\ Post Graduate Institute of Ophthalmology, Madurai, India \\ *Corresponding Author: Madhu Shekhar, Head of Department, Department of \\ Intraocular Lens and Cataract Services, Aravind Eye Hospital and Post Graduate \\ Institute of Ophthalmology, Madurai, India.
}

Received: September 25, 2020

Published: October 16, 2020

(C) All rights are reserved by Madhu Shekhar., et al.

\section{Abstract}

Objective: To analyze the demography and clinical profile of ocular emergency surgeries performed during COVID-19 pandemic in a tertiary eye care center.

Design: This is a retrospective study. We included data of the patients who underwent ocular emergency surgeries from 24.03 .2020 to 15.05.2020 (24.03.2020 was the date of commencement of national wide lockdown in our country). Data from the corresponding time of the previous year (24.03.2019 to 15.05.2019) were taken for comparative analysis.

Setting: This is a retrospective Hospital based study. The data were retrieved from electronic medical record system.

Participants: Patients who underwent emergency ocular surgery during the study period were included. 242 patients were included for 2020 study period and 948 for 2019 study period.

Results: Overall 242 patients underwent ocular emergency surgeries during the pandemic. The mean age of the patients was 41.52 \pm 22.6 , median was 45 years (Interquartile range, IQR: 24 - 60), were mostly adults 187 (79.3\%). Majority of them were males 157 (64.9\%). More than half of our patients 127 (52.69\%) presented from within $60 \mathrm{~km}$ of the point of care. History of ocular trauma was seen in 130 (53.9\%) patients and among them 42 (32.3\%) fall under the age group of 0 - 15 years. Most common indications for surgery were open globe injury 64 (26.4\%) and rhegmatogenous retinal detachment 38 (15.7\%). There was significant increase in open globe injury (from $12.8 \%$ to $26.4 \%$ ) and lens induced glaucoma (7.7\% to $13.2 \%$ ) when compared to the corresponding time of the previous year.

Conclusion: We need to educate people regarding the importance of timely treatment of ocular emergencies to get a better outcome. Health care sector should be well equipped and accessible to handle emergencies during these pandemics. Hospitals need to prepare for expected surge in patients during post pandemic era.

Keywords: Pandemic; Emergency Surgery; Ocular Trauma; Open Globe Injury

\section{Introduction}

Since being declared as a pandemic by the World health organization on $11^{\text {th }}$ March 2020, the COVID-19 continues to spread globally. By $25^{\text {th }}$ September 2020 it had spread to 216 countries with
31.7 million confirmed cases worldwide and 3.6 million in India [1].

To reduce the spread of the coronavirus, countries have promoted various unprecedented public health responses. These mea- 
sures aimed at reducing the spread of the pandemic. In India, the government ordered nationwide lockdown on $24^{\text {th }}$ March 2020 [2]. It required people to stay home, restricting movements with exception of medical emergencies. Health establishments were asked to avoid non-urgent hospitalization and suspend elective surgeries to avoid hospital related infections to vulnerable and prepare hospitals for meeting challenges posed by COVID-19.

Ocular emergencies can cause permanent vision loss if they are not recognized and treated promptly. Therefore, careful examination and appropriate treatment are important factors in preventing poor visual prognosis in ocular emergencies. But close proximity with patients during examination puts ophthalmologists under high risk of contracting infection from the patients [3]. Though uncommon conjunctivitis could be the presenting symptom of COVID-19. There are reports suggesting that Corona virus has been isolated from tear sample of COVID-19 patient [3]. All these abovementioned factors increase the risk of cross-infection, between patients and as well between health care workers (HCW) and patients in ophthalmology clinics in comparison to other specialties [4]. So, in order to reduce the transmission of infections we have implemented new safety protocols as per the guidelines provided by the All India Ophthalmological society (AIOS) [5,6].

This study describes our experience of handling emergency ocular surgeries performed at a tertiary eye care institute in India during the COVID-19 pandemic following the new safety protocols set up by our center.

\section{Materials and Methods}

This was a retrospective study done at a tertiary care dedicated ophthalmic hospital in India. We reviewed the electronic medical record of patients who underwent emergency ocular surgeries in our hospital between $24^{\text {th }}$ March 2020 and $15^{\text {th }}$ May 2020. $\left(24^{\text {th }}\right.$ March 2020 was the commencement of national wise lockdown for the pandemic in our country). Data regarding emergency surgeries done during the corresponding time interval in the previous year (24.03.2019 to 15.05.2019) was taken for comparative analysis. None of the identifiable parameters of the patient information were used for the analysis of the data. Consent form was obtained before any procedure from the patient and the attender. Study adhered to the declaration of Helsinki and institution ethics committee approval has been obtained.

Our hospital introduced new safety measures during the pandemic. These included postponements of elective surgeries; pro- viding appropriate Personal protective equipment (PPE) to all HCW; installing triage station at the entrance; screening for fever since $88 \%$ of covid-19 patients present with fever [7] and requesting patients and accompanying person to put on face masks and maintain social distance; reduction of workforce; fumigation of operation theatres every day, installation of ultra violet lamps in Heating, ventilation and air conditioning (HVAC) system; cleaning of operation theatre floor and table with appropriate disinfectants after every surgery and maintaining a gap of 15 to 20 minutes between surgeries; proper channelization of the patient flow to minimize crowding and time spent by the patients in the hospital.

\section{Data retrieval and processing}

A total of 242 patients of all ages underwent ocular emergency surgery during the study period. The data of these patients were retrieved from the electronic medical record database and segregated in a single excel sheet (Microsoft Excel ${ }^{\circledR}$ ).

Data on patient demographics, clinical presentation, ocular diagnosis and treatment modalities were used for analysis.

\section{Statistical analysis}

The data were entered into a Microsoft Excel spreadsheet and statistical analysis was performed with STATA statistical software, Version 14.0. Continuous variables were expressed as mean ( \pm standard deviation) or median (Range). Proportion test was used to assess the significant difference between two groups (2019 and 2020). p value $<0.05$ was considered as statistically significant.

\section{Results}

Overall 242 patients underwent emergency surgeries during the study period.

Age

The mean age of the patients was $41.52 \pm 22.6$ years while the median age was 45 years (IQR: 24 - 60). 55 (22.7\%) patients were children (<15 years) and 187 (72.3\%) were adults. The most common age group at presentation was 51 - 75 years 92 (38\%) (Table 1). The adult pediatric ratio was $3.4: 1$ as compared to $14.3: 1$ in the corresponding time of the previous year (Table 2).

\section{Gender}

There were 157 (64.9\%) male and 85 (35.1\%) female patients. Among them, the mean and median age were 40.1 and 44 (IQR: 21 - 60) years for male and 44.1 and 50 (28 - 61.5) years for female. The male: female ratio was $1.85: 1$ as compared to $1.91: 1$ in the corresponding time of the previous year. 


\begin{tabular}{|c|c|c|c|c|c|c|c|}
\hline \multirow{2}{*}{$\begin{array}{l}\text { Age in } \\
\text { years }\end{array}$} & \multicolumn{3}{|c|}{$\begin{array}{c}\text { COVID-19 pandemic } \\
(24.03 .2020-15.03 .2020)\end{array}$} & \multicolumn{3}{|c|}{$\begin{array}{c}\text { Corresponding period last year } \\
\text { (24.03.2019-15.03.2019) }\end{array}$} & \multirow{2}{*}{$\begin{array}{c}\text { p value } \\
\text { (Total 1 } \\
\text { vs Total 2) }\end{array}$} \\
\hline & Male & Female & $\begin{array}{l}\text { Total } 1 \\
\text { n (\%) }\end{array}$ & Male & Female & $\begin{array}{l}\text { Total } 2 \\
\text { n (\%) }\end{array}$ & \\
\hline $0-15$ & 36 & 19 & $55(22.7 \%)$ & 48 & 14 & $62(6.5 \%)$ & \multirow[t]{6}{*}{$<0.001$} \\
\hline $16-25$ & 8 & 1 & $9(3.7 \%)$ & 37 & 7 & 44 (4.6\%) & \\
\hline $26-50$ & 54 & 25 & $79(32.6 \%)$ & 176 & 97 & $273(28.7 \%)$ & \\
\hline $51-75$ & 58 & 34 & $92(38 \%)$ & 347 & 199 & $546(57.5 \%)$ & \\
\hline$>75$ & 1 & 6 & $7(8.2 \%)$ & 14 & 9 & $23(9.2 \%)$ & \\
\hline Total & 157 & 85 & 242 & 622 & 326 & 948 & \\
\hline
\end{tabular}

Table 1: Demographic analysis of patients undergoing emergency surgeries during the pandemic and comparing with the corresponding time of the previous year.

\begin{tabular}{|c|c|c|c|}
\hline & $\begin{array}{c}\text { COVID-19 pandemic } \\
(24.03 .2020-15.03 .2020)\end{array}$ & $\begin{array}{l}\text { Corresponding period last year } \\
(24.03 .2019-15.03 .2019)\end{array}$ & $P$ value \\
\hline Pediatric age group & 55 & 62 & \multirow[t]{2}{*}{$<0.001$} \\
\hline Adult age group & 187 & 886 & \\
\hline
\end{tabular}

Table 2: Comparison between adult and pediatric age group during the pandemic and corresponding time of the previous year.

\section{Geographic data}

Majority of patients was from the same district 84 (34.8\%) and 43 (17.8\%) were from 45 - $60 \mathrm{~km}$ from our hospital.

Mean time duration taken by the patient to present to the hospital was $7.02 \pm 6.8$ days and median was 5 days (IQR: 2 - 10).

\section{Trauma}

Out of 242 patients who underwent emergency surgeries, 130 (53.9\%) had history of ocular trauma. Most common mode of trauma was agriculture related 47 (36.1\%) followed by children playing with sharp objects 42 (32.3\%). Rest of the details regarding the trauma is represented in table 3. Most common age group with history of trauma was 26 - 50 years 54 (41.5\%) followed by 0 - 15 years $42(32.3 \%)$.

\section{Indications for surgery}

Most common indication for surgery was open globe injury 64 (26.4\%) followed by retinal detachment 37 (15.3\%). Other indications for the surgeries are represented in table 4.

\begin{tabular}{|l|c|}
\hline Mode of Trauma & $\begin{array}{c}\text { n (\%) } \\
\mathbf{n}=\mathbf{1 3 0}\end{array}$ \\
\hline Playing with sharp objects & $42(32.3)$ \\
\hline Manual work & $19(14.6)$ \\
\hline Animal care & $11(8.5)$ \\
\hline Agriculture & $47(36.1)$ \\
\hline Home activities & $6(4.6)$ \\
\hline Road traffic accidents (RTA) & $3(2.3)$ \\
\hline Crackers & $1(0.7)$ \\
\hline Others & $1(0.7)$ \\
\hline
\end{tabular}

Table 3: Mechanism of ocular trauma.

\begin{tabular}{|l|c|}
\hline Indications for surgery & $\begin{array}{c}\text { n (\%) } \\
\mathbf{n} \mathbf{2 4 2}\end{array}$ \\
\hline Trauma related & $64(26.4)$ \\
\hline Open globe injury & $8(3.3)$ \\
\hline Closed globe injury & $5(2.1)$ \\
\hline Corneal foreign body & $5(2.1)$ \\
\hline Lid laceration & \\
\hline Lens related & $27(11.2)$ \\
\hline Traumatic cataract & $32(13.2)$ \\
\hline Lens induced glaucoma & $2(0.8)$ \\
\hline Hypermature cataract & \\
\hline Glaucoma & $4(1.7)$ \\
\hline Neovascular glaucoma & $3(1.2)$ \\
\hline Angle closure glaucoma & $1(0.4)$ \\
\hline Congenital glaucoma & \\
\hline Infectious eye disease & $6(2.5)$ \\
\hline Pan ophthalmitis & $14(5.8)$ \\
\hline Traumatic endophthalmitis & $6(2.5)$ \\
\hline Endogenous endophthalmitis & $2(0.8)$ \\
\hline Scleral abscess & $3(1.2)$ \\
\hline Lacrimal abscess & $3(1.2)$ \\
\hline Lid abscess & $38(15.7)$ \\
\hline Posterior segment pathology & $10(4.1)$ \\
\hline Retinal detachment & $9(3.8)$ \\
\hline Vitreous haemorrhage & \\
\hline Others & \\
\hline & \\
\hline
\end{tabular}

Table 4: Indications for emergency surgeries during the covid-19 pandemic. 


\section{Surgical intervention}

Most common emergency surgery performed was pars plana vitrectomy 72 (29.7\%) for retinal detachments, non-clearing vitreous hemorrhage and endophthalmitis and corneoscleral tear repair $52(21.5 \%)$ for open globe injury followed by manual small incision cataract surgery (SICS) 42 (17.4\%) for lens induced glaucoma and traumatic cataracts. Rest of the clinic-wise emergency surgeries performed is represented in table 5 .

\begin{tabular}{|c|c|}
\hline Types of surgery & $\begin{array}{c}\text { n (\%) } \\
\text { n = } 242\end{array}$ \\
\hline \multicolumn{2}{|l|}{ Cornea } \\
\hline Corneo scleral tear repair & $52(21.5)$ \\
\hline Corneal tear repair +lens removal & $9(3.7)$ \\
\hline Corneal foreign body removal & $5(2.1)$ \\
\hline \multicolumn{2}{|l|}{ Cataract } \\
\hline SICS (lens induced glaucoma+ traumatic cataract) & $42(17.4)$ \\
\hline Lens removal & $8(3.3)$ \\
\hline IOL explantation & $1(0.4)$ \\
\hline \multicolumn{2}{|l|}{ Orbit and oculoplasty } \\
\hline Lid suturing & $5(2.1)$ \\
\hline Enucleation/evisceration & $11(4.5)$ \\
\hline Incision and drainage & $8(3.3)$ \\
\hline Orbital floor repair & $1(0.4)$ \\
\hline \multicolumn{2}{|l|}{ Vitreoretinal } \\
\hline Parsplana vitrectomy & $72(29.7)$ \\
\hline Intravitreal injection & $11(4.5)$ \\
\hline \multicolumn{2}{|l|}{ Glaucoma } \\
\hline Trabeculectomy & $5(2.1)$ \\
\hline Cyclodestructive procedure & $4(1.6)$ \\
\hline Others & $8(3.3)$ \\
\hline
\end{tabular}

Table 5: Types of emergency surgeries done during the COVID-19 pandemic.

Ocular emergency surgeries done during the corresponding time of the previous year was 984 which decreased to 260 in 2020. There was significant increase in open globe injury and lens induced glaucoma from $12.8 \%$ to $26.4 \%(\mathrm{p}=0.016)$ and $7.7 \%$ to $13.2 \%$ respectively $(\mathrm{p}<0.001)$. Rest of the comparative analysis is represented in table 6 and figure 1.

\begin{tabular}{|l|c|c|c|}
\hline Diagnosis & $\begin{array}{c}\text { In 2019 } \\
\mathbf{n = 9 4 8 ( \% )}\end{array}$ & $\begin{array}{c}\text { In 2020 } \\
\mathbf{n = 2 4 2 ( \% )}\end{array}$ & p value \\
\hline Trauma & & \\
\hline Open globe injury & $121(12.8)$ & $64(26.4)$ & $0.016^{\mathrm{a}}$ \\
\hline Closed globe injury & $31(3.3)$ & $8(3.3)$ & $>.99$ \\
\hline Lid tear & $17(1.8)$ & $5(2.0)$ & 0.98 \\
\hline Corneal foreign body & $10(1.0)$ & $5(2.0)$ & 0.87 \\
\hline Lens related & $243(25.6)$ & $27(11.2)$ & 0.093 \\
\hline Traumatic cataract & $121(12.8)$ & $2(0.8)$ & 0.61 \\
\hline $\begin{array}{l}\text { Hyper mature cata- } \\
\text { ract }\end{array}$ & $73(7.7)$ & $32(13.2)$ & $<0.001^{\text {a }}$ \\
\hline $\begin{array}{l}\text { Lens induced glau- } \\
\text { coma }\end{array}$ & \begin{tabular}{l} 
\\
\hline Retina posterior segment pathology
\end{tabular} & \\
\hline $\begin{array}{l}\text { Endophthalmitis } \\
\text { (traumatic+ endog- } \\
\text { enous) }\end{array}$ & $42(4.4)$ & $26(10.7)$ & $0.004^{\mathrm{a}}$ \\
\hline \begin{tabular}{l} 
Retinal detachment \\
\hline \begin{tabular}{l} 
Others \\
\hline
\end{tabular}
\end{tabular} & $238(25.1)$ & $38(15.7)$ & 0.21 \\
\hline
\end{tabular}

Table 6: Comparison of indications for emergency surgeries during covid-19 pandemic with corresponding period last year. ${ }^{\mathrm{a}}$ statistically significant.

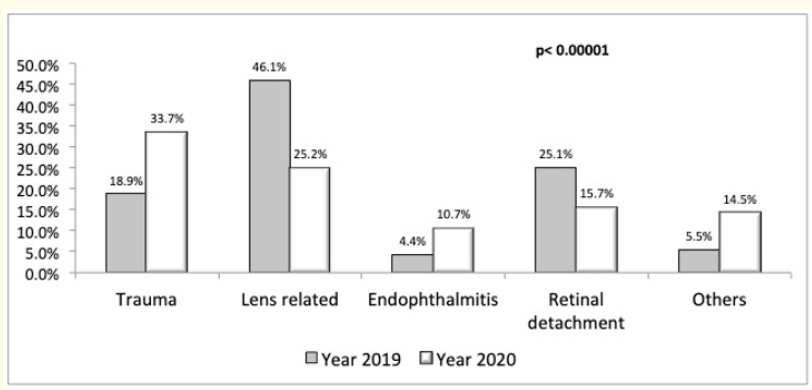

Figure 1: Bar chart comparing the indications for emergency surgery during the pandemic and corresponding time of the previous year.

\section{Discussion}

Since the declaration of lockdown due to this pandemic patient presenting to our outpatient department significantly dropped to $3.5 \%$ when compared to the previous year [8]. Though many authors reported on practice guidelines for ophthalmic surgery dur- 
ing the pandemic $[5,6,9]$, decrease in ocular emergency surgeries have not been properly reported so far. Only two letters to the editor have been published $[10,11]$.

There was a striking $95.98 \%$ decrease in number of surgeries done in our hospital during the lockdown when compared to corresponding time of the previous year. Suspension of elective surgeries could be attributed to it. There was also $72.6 \%$ decrease in ocular emergencies requiring surgical intervention when compared to the corresponding time of the previous year. Valderrama., et al. reported a 58.9\% decrease in acute care surgery [12]. Anecdotal reports suggest that this is happening in other medical specialties as well $[13,14]$. This drop can be due to travel restrictions and fear of contracting COVID-19 on visiting the hospital. Importance of not delaying the emergency care should be emphasized to avoid permanent blindness and ocular morbidity. Our hospital had also set up Tele-ophthalmology consultation during the pandemic where based on the complaint, the patients can be triaged as emergency and non-emergency by qualified personnel and they will guide the patient accordingly.

Out of the 242 patients who underwent emergency surgery only $35.1 \%$ were female, $2.90 \%$ were above 75 years of age, $20.75 \%$ belonged to pediatric age group and $8.68 \%$ people living in a location $>200 \mathrm{~km}$ from our hospital. This disparity highlights the difficulty faced by vulnerable age group in accessing eye care and the impact of travel restrictions due to the pandemic. Such pandemic gives us the opportunity to deploy mobile clinics to fill the gaps in healthcare, reaching socio-economically underserved populations in both urban and rural areas [15].

Among the patients with history of ocular trauma, $32.5 \%$ belonged to the age group of 0 - 15 years of age. Most common mode of trauma in this age group was playing with sharp common household objects. It may be attributed to closure of schools, public parks and playgrounds which forced the children to play inside the house. Pellegrini., et al. also reported increase in eye injuries from violence and home activities during the lockdown due to this pandemic [16]. So, it is important to educate the parents to safely engage the children at home during this pandemic.

Common indications for surgery at our hospital were open globe injury and rhegmatogenous retinal detachment. Similar findings were reported by Tang., et al. [11]. There was a significant increase in emergency surgeries due to lens induced glaucoma when compared to corresponding time of the previous year. It could be because of suspension of elective cataract surgeries during the lockdown and suspension of community outreach programs which benefits elderly people from remote areas for whom access to eye care is difficult. We can expect a surge in such cases of mature cataracts, lens induced glaucoma and hypermature cataract in coming months and prepare ahead to cater to them.

The main limitation of this study was that patients undergoing non-surgical treatment of ocular emergencies could not be studied. The retrospective design of the project could also be considered a weakness. The main strength of our paper was that detailed analysis of a significant number of patients were done in a tertiary eye care hospital located in a state which has the second highest number of COVID-19 cases in the country.

\section{Conclusion}

Our study emphasis on timely intervention for ocular emergencies to get a better outcome and encourage them to use Tele-ophthalmology and other new modalities to increase the accessibility to health care. We need to educate the people to safely engage children at home to prevent ocular trauma. During this pandemic health care sector should be well equipped and accessible for nonCOVID-19 emergencies. We hope our experience with new safety measures could contribute for better management of patients requiring emergency ophthalmic surgeries during this pandemic and prepare for the surge of patients in the days to come, safeguarding the health of our patients and also our care givers.

\section{Conflict of Interest}

Nil.

\section{Funding}

Nil.

\section{Ethical Approval}

All procedures performed in studies involving human participants were in accordance with the ethical standards of the institutional and national research committee and with the 1964 Helsinki declaration and its later amendments or comparable ethical standards.

\section{Informed Consent}

Informed consent was obtained from all individual participants before any interventions were performed. 


\section{Bibliography}

1. Coronavirus disease (COVID-19).

2. COVID-19: Lockdown across India, in line with WHO guidance | | UN News.

3. Hu Yaguang., et al. "Positive Detection of SARS-CoV-2 Combined HSV1 and HHV6B Virus Nucleic Acid in Tear and Conjunctival Secretions of a Non-Conjunctivitis COVID-19 Patient with Obstruction of Common Lacrimal Duct". Acta Ophthalmologica 2 (2020): 1-5.

4. Olivia Li., et al. "Preparedness among Ophthalmologists: During and Beyond the COVID-19 Pandemic". Ophthalmology American Academy of Ophthalmology 127.5 (2020): 569-572.

5. Reddy JagadeshC., et al. "A New Normal with Cataract Surgery during COVID-19 Pandemic". Indian Journal of Ophthalmology 68.7 (2020): 1269.

6. Sengupta S., et al. "All India Ophthalmological Society - Indian Journal of Ophthalmology consensus statement on preferred practices during the COVID-19 pandemic". Indian Journal of Ophthalmology 68 (2020): 711-724.

7. Huang Chaolin., et al. "Clinical Features of Patients Infected with 2019 Novel Coronavirus in Wuhan, China". The Lancet 395.10223 (2020): 497-506.

8. Babu Naresh., et al. "To Evaluate the Effect of COVID-19 Pandemic and National Lockdown on Patient Care at a TertiaryCare Ophthalmology Institute". Indian Journal of Ophthalmology 68.8 (2020): 1540-1544.

9. Gharebaghi, Reza., et al. "COVID-19: Preliminary Clinical Guidelines for Ophthalmology Practices". Medical Hypothesis, Discovery and Innovation Ophthalmology Journal 9.2 (2020): 149-158.

10. Du, Hao., et al. "Practical Experience on Emergency Ophthalmic Surgery during the Prevalence of COVID-19". Graefe's Archive for Clinical and Experimental Ophthalmology 258 (2020): 1-3.

11. Tang, Emily W. H.., et al. "Emergency Ophthalmic Surgeries during COVID-19-a Hong Kong Perspective". Graefe's Archive for Clinical and Experimental Ophthalmology 2 (2020): 1-2.

12. Cano-Valderrama Oscar., et al. "Acute Care Surgery during the COVID-19 Pandemic in Spain: Changes in Volume, Causes and Complications. A Multicentre Retrospective Cohort Study". International Journal of Surgery 80 (2020): 157-161.

13. Laura E Wong., et al. "Where Are All the Patients? Addressing Covid-19 Fear to Encourage Sick Patients to Seek Emergency Care". NEJM Catalyst (2020): 1-12.
14. Hartnett Kathleen P., et al. "Impact of the COVID-19 Pandemic on Emergency Department Visits - United States, January 1, 2019-May 30, 2020". Morbidity and Mortality Weekly Report 69.23 (2020): 699-704.

15. Attipoe-Dorcoo Sharon., et al. "Mobile Health Clinic Model in the COVID-19 Pandemic: Lessons Learned and Opportunities for Policy Changes and Innovation". International Journal for Equity in Health 19 (2020).

16. Pellegrini Marco., et al. "Changing Trends of Ocular Trauma in the Time of COVID-19 Pandemic". Eye (Basingstoke) 34.7 (2020): 1248-1250.

\section{Assets from publication with us}

- Prompt Acknowledgement after receiving the article

- Thorough Double blinded peer review

- Rapid Publication

- Issue of Publication Certificate

- High visibility of your Published work

Website: www.actascientific.com/

Submit Article: www.actascientific.com/submission.php Email us: editor@actascientific.com

Contact us: +919182824667 